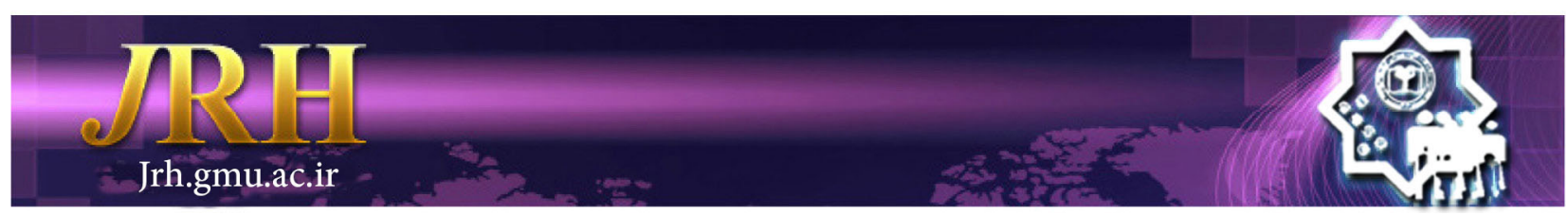

\title{
Predictors of protection motivation to prevent home injuries among mothers with children under 5 year- old
}

Tahereh Rahimi ${ }^{1}$, Reza Mirzaee ${ }^{2}$, Ali Kamali ${ }^{3}$, Reza Faryabi ${ }^{4}$

\author{
Journal of Research \& Health \\ Social Development \& Health Promotion \\ Research Center \\ Vol. 8, No. 3, May \& Jun 2018 \\ Pages: 255- 261 \\ DOI: $10.29252 / j r h .8 .3 .255$ \\ Original Article
}

1. Department of Health Education and Promotion, School of Health, Yazd Shahid Sadoughi University of Medical Sciences, Yazd, Iran

2. Department of Nursing, School of Nursing and Midwifery, Jiroft University of Medical Sciences, Jiroft, Iran

3. Department of Medicine, School of Medicine, Jiroft University of Medical Sciences, Jiroft, Iran 4. Correspondence to: Department of Public Health, School of Health, Jiroft University of Medical Sciences, Jiroft, Iran

Email: r.faryabi@jmu.ac.ir

Received: 6 Agu 2016

Accepted: 8 Nov 2016

How to cite this article: Rahimi T, Mirzaee R, Kamali A, Faryabi R. Predictors of protection motivation to prevent home injuries among mothers with children under 5 year-old. $J$ Research Health2018; 8(3): 255- 261.

\begin{abstract}
Unintentional injuries are major cause of death and disability in children. In this regard, mothers play important role in adopting preventive measures to avoid these injuries. The aim of this study was to determine the predictors of protection motivation to prevent home injuries among mothers with children under 5 yearold. This study was performed on 204 mothers having children under 5 year-old in health centers. Proportional stratified random sampling was use as sampling method. The inclusion criteria were living in Jiroft city, ability to read and write, having at least one child under 5 year-old and desire to participate in the study. A researcher-made with 41 items questionnaire was used to measure demographics characteristics and protection motivation theory constructs in terms of home injuries. The results showed that there was significant relationship between mean scores of protection motivation and perceived vulnerability, perceived severity, response efficacy, self-efficacy, response costs and fear. The results of linear regression analysis showed that selfefficacy, fear and response costs could predict $20 \%$ of variance of motivation to protect from home-related injuries. Considering that self-efficacy, response cost, and fear could predict protection motivation among mothers so use of such constructs in health promotion interventions can improve the safety behaviors of mothers at home.
\end{abstract}

Keywords: Children, Fear, Home Accidents, Motivation, Self Efficacy

\section{Introduction}

Injuries are recognized as significant threats to child health among the leading causes of death and severe disability among children aged 1-4 years around the world [1,2]. The majority of childhood injuries occur at home. Children less than 5 year-old are more vulnerable to these events due to the lack of awareness about dangers of the surrounding environment $[3,4]$. It is estimated that in the United States about 1.4 million children under 5 year-old annually were refereed emergency room departments due to unintentional injuries [5]. The injury not only affects injured child but also the influence family and the society with approximate annual burden of 87 billion dollars [6]. Among the home-related injuries, drowning and burns are about $35 \%$ of the deaths among children aged 1 to 9 years. In addition, falls is the main cause of non-fatal injuries among three million children who annually receive emergency medical 
care $[7,8]$. A study in Iran reported prevalence of home injuries in children younger than 5 year-old as $40 \%$ among which the commonest were falling (30.1\%), swallowing foreign bodies $(22 \%)$, burns $(16.8 \%)$, and poisoning (4.11\%) [9]. Several factors influence household injuries in children which include child factors (young age and being male), parent factors (inappropriate home design, lack of supervising children's activities, low education level, and lack of knowledge about the potential dangers at home), and family factors (low socioeconomic status, large number of children at home, living in crowded and poor neighborhood and absence of mother from home for more than 8 hours day) [10-14]. A comprehensive examination of behavioral factors can help us achieve a suitable approach for prevention of home injuries. In this regard, models and theories can explain behavior and identify measures required to change it. Indeed, through application of theory or model, the characteristics of individual and surrounding environment that somehow affects the behavior can be detected [15]. The Protection Motivation Theory is appropriate framework particularly adapted in protective or precautionary behavioral interventions. This theory was developed by Rogers in 1975 explain the effect of fear on attitudes and health behaviors and considers that fear has significant effect on behavior's selection [16]. According to this theory; adoption of recommended health behavior is the direct result of individuals' motivation to protect themselves [17]. Despite the importance of this issue, few studies are available about injuries and related factors especially based on protection motivation theory $[18,19]$. This means this theory is appropriate to explain home injuries concerning on health threats. This study aimed to determine predictors of protection motivation to prevent home injuries based on the protection motivation theory among mothers with children younger than 5 year-old in Jiroft city, Iran.

\section{Method}

This cross-sectional study aimed to determine the predictors of protection motivation to prevent home injuries using the protection motivation theory. It was carried out on mothers with children younger than 5 yearold in Jiroft health centers during July to October 2015. The sampling was performed by proportional stratified random sampling. To this end, 8 health centers of Jiroft city were selected as stratums. Then, list of the households with the inclusion criteria was prepared for each center. According to the random numbers table, a total of 204 cases were involved. The inclusion criteria were living in Jiroft city, ability to read and write, having at least one child under 5 year-old, and desire to participate in the study. A researchermade questionnaire consisting of two sections was used to gather the data. The first section was on demographic characteristics; including mother's age, parent occupation, parent education level, number of children, history of previous home injuries and family income. The second section consisted of 32 items related to the protection motivation as follows; one item on protection motivation, three items on perceived severity, seven items on perceived vulnerability, three items on fear, four items on response efficacy, eight items on self-efficacy, four items on response costs and two points on perceived rewards. Each item was scored by the participants on a 5-point Likert scale (ranging from strongly disagree to strongly agree).

The validity of the questionnaire was assessed by measuring Content Validity Ratio (CVR) and Content Validity Index (CVI). CVI and CVR were determined as 0.76 and 0.80 by using opinions obtained from the health education expert panel. The test-retest (within 10 days) was used for protection motivation construct (the Spearman correlation coefficient was 0.71 ) to assess the reliability, while internal consistency was used for other constructs. For this purpose, a pilot study was performed and the questionnaire was completed by 20 women having same conditions as the participants of the current study. The final Cronbach's alpha was obtained for the evaluated items as follows 0.90 for self-efficacy, 0.86 for perceived vulnerability, 
0.72 for perceived severity, 0.78 for response costs, 0.70 for response efficacy, 0.79 for perceived rewards, and 0.76 for fear that is considered acceptable. The data were analyzed by using the SPSS-18. Descriptive statistics were used to examine the characteristics of women. The Pearson correlation test was used to examine the correlation between the protection motivation theory constructs and linear regression analysis to predict protection motivation $(p<0.05)$.

\section{Results}

In the present study, the age range was 16-49 year-old and most women were in the 25-29 age group. $77.5 \%$ women were housewives and $46.1 \%$ women had higher education. $44.6 \%$ of the women had one child and the child sex was female for $50 \%$ of the participants. There was history of home injuries in 46 children $(22.5 \%)$, which included 25 cases of burn (54.3\%), 8 cases of poisoning (17.3\%), 7 cases of fallings from stairs $(15.2 \%), 5$ cases of cuts $(10.8 \%)$, and 1 case of asphyxiation (2.1\%). The family income of less than one million Toman monthly (approximately 300 dollars) was reported in $66.7 \%$ (Table 1). According to the results of one-way analysis of variance, there was significant relationship between mean scores of protection motivation and husband's occupation $\quad(p=0.01)$. No statistically significant relationship was observed between the mean scores of protection motivation and mother's age group $(p=0.47)$, mother's education level $(\mathrm{p}=0.81)$, father's education level $(p=0.51)$, mother's occupation $(p=0.97)$, and number of children $(\mathrm{p}=0.06)$. Also according to the independent samples test, no statistically significant relationship was found between mean scores of mother's protection motivation who had girl or boy $(\mathrm{p}=0.19)$ and family income $(\mathrm{p}=0.64)$.

Table 1 Distribution of demographic characteristics in women participating in study $(n=204)$

\begin{tabular}{|c|c|c|}
\hline $\begin{array}{l}\text { Demographic } \\
\text { characteristics }\end{array}$ & & Number (\%) \\
\hline \multirow[t]{4}{*}{ Age group } & $\leq 25$ year & $35(17.1)$ \\
\hline & 25- 29 years & $64(31.4)$ \\
\hline & 30- 34 years & $61(29.9)$ \\
\hline & $\geq 35$ years & $44(21.6)$ \\
\hline \multirow[t]{2}{*}{ Occupation } & Household duties & $158(77.5)$ \\
\hline & Employee & $46(22.5)$ \\
\hline \multirow[t]{3}{*}{$\begin{array}{l}\text { Husband's } \\
\text { Occupation }\end{array}$} & Employee & $62(30.4)$ \\
\hline & Casual labourer & $25(12.3)$ \\
\hline & Self-employed & $117(57.3)$ \\
\hline \multirow[t]{2}{*}{ Education level } & $\leq 12$ th grade & $110(53.9)$ \\
\hline & $>12$ th grade & $94(46.1)$ \\
\hline \multirow[t]{2}{*}{$\begin{array}{l}\text { Husband education } \\
\text { Level }\end{array}$} & $\leq 12$ th grade & $136(66.7)$ \\
\hline & $>12$ th grade & $68(33.3)$ \\
\hline \multirow[t]{3}{*}{ Number of children } & 1 & $91(44.6)$ \\
\hline & 2 & $70(34.3)$ \\
\hline & $\geq 3$ & $43(21.1)$ \\
\hline \multirow[t]{2}{*}{ Child gender } & Boy & $102(50)$ \\
\hline & Girl & $102(50)$ \\
\hline \multirow[t]{2}{*}{$\begin{array}{l}\text { History of home } \\
\text { injuries }\end{array}$} & Yes & $46(22.5)$ \\
\hline & No & $158(77.5)$ \\
\hline \multirow[t]{2}{*}{$\begin{array}{l}\text { Monthly family } \\
\text { income }\end{array}$} & $\leq 300 \$$ & $136(66.7)$ \\
\hline & $\geq 300 \$$ & $68(33.3)$ \\
\hline
\end{tabular}


Mean, standard deviation and range scores of the protection motivation theory constructs are given in Table 2.
The correlation between protection motivation theory constructs is provided in Table 3.

Table 2 Mean, standard deviation and range of attainable score of protection motivation theory in women participating in study $(n=204)$

\begin{tabular}{lcc}
\hline Construct & Mean \pm SD & Range of attainable score \\
\hline Protection motivation & $4.48 \pm 0.85$ & $1-5$ \\
Perceived vulnerability & $23.21 \pm 8.74$ & $7-35$ \\
Perceived severity & $11.65 \pm 3.48$ & $3-15$ \\
Perceived rewards & $5.09 \pm 2.45$ & $2-10$ \\
Response efficacy & $16.59 \pm 3.48$ & $4-20$ \\
Self-efficacy & $28.31 \pm 6.16$ & $8-40$ \\
Response costs & $10.37 \pm 4.36$ & $4-20$ \\
Fear & $11.97 \pm 2.88$ & $3-15$ \\
\hline
\end{tabular}

According to the Pearson correlation test, there is significant correlation between mean value of protection motivation, and perceived vulnerability $(\mathrm{p}=0.012)$, perceived severity $(p=0.001)$, response efficacy $(p=0.006)$, selfefficacy $(p<0.001)$, response costs $(p=0.005)$, and fear $(\mathrm{p}<0.001)$.
Table 4 shows the predictors of protection motivation in women of current study. According to the results of linear regression analysis self-efficacy, fear, and response efficacy explain $20 \%$ of the variance of protection motivation for prevention of home injuries.

\begin{tabular}{|c|c|c|c|c|c|c|c|c|}
\hline Constructs & 1 & 2 & 3 & 4 & 5 & 6 & 7 & 8 \\
\hline Protection motivation & 1 & & & & & & & \\
\hline Perceived vulnerability & $0.17 *$ & 1 & & & & & & \\
\hline Perceived vulnerability & $0.22 * *$ & $0.61 * *$ & 1 & & & & & \\
\hline Perceived rewards & 0.12 & $0.22 * *$ & 0.13 & 1 & & & & \\
\hline Response efficacy & $0.19 * *$ & .011 & $0.20 * *$ & 0.08 & 1 & & & \\
\hline Self-efficacy & $0.37 * *$ & $0.17^{*}$ & $0.24 * *$ & $-0.18^{* *}$ & $0.51 * *$ & 1 & & \\
\hline Response costs & $-0.19 * *$ & $0.18 * *$ & 0.09 & $0.45^{* *}$ & -0.09 & $-0.25^{* *}$ & 1 & \\
\hline Fear & $0.32 * *$ & $0.29 * *$ & $0.35 * *$ & -0.03 & $0.55 * *$ & $-0.48 * *$ & 0.03 & 1 \\
\hline
\end{tabular}

$\mathrm{p}<0,05^{*}, \mathrm{p}<0,01 * *$

Table 4 Predictors of protection motivation of home injuries in women participating in study $(n=204)$

\begin{tabular}{lcccccc}
\hline Variable & B & SE & Beta & P & F & $\mathrm{R}^{2}$ \\
\hline Constant (a) & 3.06 & 0.36 & & 0.001 & 8.30 & 20 \\
Self-efficacy & 0.03 & 0.01 & 0.25 & 0.002 & & \\
Response costs & -0.02 & 0.01 & -0.15 & 0.028 & & \\
Fear & 0.06 & 0.02 & 0.20 & 0.017 & & \\
\hline
\end{tabular}

\section{Discussion}

The results showed that self-efficacy, fear, and response cost constructs could explain $20 \%$ of the variance of motivation protection related to home injuries preventive behavior in mothers with children under 5 year-old in Jiroft. Consistent with the results in this study, Fathi Shekhi and colleagues' research indicated $20 \%$ of home injuries precautionary behavior change was expressed by perceived self-efficacy, perceived barriers, and knowledge [20]. Beirens et al. reported selfefficacy, response efficacy, advantages of 
safe behaviors along with some demographic variables such as children who cannot walk and non-Dutch mothers explained $24 \%$ of the variance in the use of stair gates in parents with children aged 11-18 months [18]. Also Russel and Champion demonstrated that in addition to self-efficacy, mothers' beliefs about injury and its prevention and their perceptions of social expectations about safety at home could explain $26 \%$ of the variance of home injuries [21]. According to the results obtained in the current study and few studies about preventive behavior of home-related injuries used the protection motivation theory $[18,19]$, it seems application of this theory can be helpful to explain factors associated with home injuries in children. In this study, selfefficacy as the most important predictor was positively correlated with maternal protection motivation. According to the results reported by Hendrickson, mothers with higher selfefficacy have more safety behavior at home and their children faced fewer risks [22].

In this study, response cost as another predictor had negative correlation with motivation protection and self-efficacy. This finding is consistent with Beirens and Beirens $[18,19]$. The response cost often expressed as any cost (money, personal, time, or effort) in relation to the recommended behavior [17]. Greening and Stoppelbein argued response cost as the barrier of behavior [23]. Barriers may include factors such as high cost of safety equipment, living in rented house, overcrowding residential, and lack of support for children [24]. Teaching necessary skills to adopt safe behaviors and applying some strategies to overcome perceived costs would enhance women's self-efficacy.

The findings of the study showed that fear of injury at home were another positive factor that predicts motivation protection. Some studies also show that most parents are concerned about the safety of their children at home and this concern and fear cause to take precautions to avoid injuries [25]. Morrongiello et al. considered the main concerns of women with regard to home accidents as falls, poisoning, swelling and bruising, choking, drowning and cuts [26]. It is necessary health professionals warn mothers about possibility of household injuries. This can increase the fear of danger and raise concern in mothers. In this way, the mothers' precautionary measures may be improved at home and children's playground. The results indicated that response efficacy, perceived vulnerability, and perceived severity did not predict motivation protection, even though these items have direct correlation with motivation protection. Fathi Shekhi et al. found that mothers' performance on prevention of accidents and injuries in children directly were influenced by perceived benefit, perceived barriers, perceived susceptibility and self-efficacy [27]. Beirens et al. stated parents keeping medicines and cleaning products out of reach of children to prevent poisoning at home have higher response efficacy and severity but lower perceived vulnerability [19]. Also Morrongiello and colleagues showed mothers were not sensitive to the possibility of occurrence of any damage. For example while their perceived vulnerability about possibility of falling was high, it was low about poisoning [26]. Beirens et al. that found perceived severity in the parents that did not use stair gate at home was lower than that in those used stair gate. There is also a statistically significant relationship between self efficiency and benefits of safe and protective behaviors [18]. These factors should be strengthened in educational interventions designed for parents to highlight the messages on benefits of preventive behaviors. Providing statistics of childhood injuries can be effective to enhance parents' understanding of the vulnerability of their children's accidents. In the present study, fathers' occupation was associated with mothers' motivation protection about home injuries. In other studies, socioeconomic and sociodemographic variables such as poverty, young parents, low levels of parental education and immigration status are related to childhood home injuries [24,28,29]. As fathers are partly responsible for child care, survey of their perceptions can be useful in 
recommendation of appropriate measures to reduce household injuries.

The limitation of this study was being carried out only in the urban area of Jiroft and also lack of participation of illiterate mothers in the study. In this regard, it is recommended to perform similar studies in rural areas and illiterate mothers.

\section{Conclusion}

Findings of this study showed self-efficacy, response costs and fear are important factors to predict motivation protection of home injuries in mothers of children younger than 5 year-old. So, health promotion interventions could be applied by appropriate strategies to influence these structures and ultimately improve safety behaviors of mothers at home.

\section{Acknowledgements}

The present study was approved in the Ethics Committee of Jiroft University of Medical Sciences (IR.JMU.REC.1395-35). The authors would like to thank the research deputy in Jiroft University of medical sciences, Jiroft department of health center, prevention and control of diseases unit and staffs of health centers for their kindly assistance.

\section{Contribution}

Study design: TR, RF

Data collection and analysis: TR, RF, AK, RM Manuscript preparation: TR, RF, AK, RM

\section{Conflict of Interest}

"The authors declare that they have no competing interests."

\section{Funding}

The authors received financial support for this research from Jiroft University of Medical Sciences.

\section{References}

1 - Towner E, Towner J. Child injury in a changing world. Glob Public Health2009; 4(4): 402-13.

2- Grossman DC, Rivara FP.. Injury control in childhood. Pediatr Clin North Am1992; 39(3): 471-85.

3- Paes CE, Gaspar VL. Unintentional injuries in the home environment: Home safety. $J$ Pediatr (Rio J)2005; 81(5): 146-54.

4- Atak N, Karaoğlu L, Korkmaz Y, Usubütün S. A household survey: unintentional injury frequency and related factors among children under five years in Malatya. Turk J Pediatr2010; 52(3): 285-93.

5- Phelan KJ, Khoury J, Kalkwarf H, Lanphear B. Residential injuries in US children and adolescents. Public Health Rep2005; 120 (1): 63-70.

6- Harvey A, Towner E, Peden M, Soori H, Bartolomeos $\mathrm{K}$. Injury prevention and the attainment of child and adolescent health. Bull World Health Organ2009; 87(5): 390-4.

7- Bernard SJ, Paulozzi LJ, Wallace DL, et al. Fatal injuries among children by race and ethnicity United States, 1999-2002. MMWR Surveill Summ2007; 56(SS05): 1-16.

8- Borse NN, Gilchrist J, Dellinger AM, Rudd RA, Ballesteros MF, Sleet DA. Unintentional childhood injuries in the United States: Key findings from the CDC childhood injury report. J Safety Res2009; 40(1): 71-4.

9- Nouhjah S, Ghanavatizadeh A, Eskandri N, Daghlavi M. Prevalence of non-fatal home injuries and its related factors among children attending health centers in Ahvaz: a pilot study. Hakim Res J2012; 15(3): 238-42. 10- LeBlanc JC, Pless IB, King WJ, et al. Home safety measures and the risk of unintentional injury among young children: A multicentre case-control study. CMAJ2006; 175(8): 883-7.

11- Qiu X, Wacharasin C, Deoisres W, Yu J, Zheng Q. Characteristics and predictors of home injury hazards among toddlers in Wenzhou, China: A communitybased cross-sectional study. BMC Public Health2014; 14: 638.

12- Mayes S, Roberts MC, Stough CO. Risk for household safety hazards: Socioeconomic and sociodemographic factors. J Safety Res 2014; 51: 87-92. 13- Hatamabadi H, Mahfoozpour S, Forouzanfar M, Khazaei A, Yousefian S, Younesian S. Evaluation of parameter related to preventative measures on the child injuries at home. J Saf Promot Inj Prevent2013; 1(3): 140-9.

14- Greenberger C, Korn L. Knowledge, attitudes and behaviors of Jewish Ultra Orthodox mothers as related to toddlers' safety in the home environment. Int $J$ Child Adolesc Health2011; 4(4): 383-96.

15- Glanz K, Rimer BK, Viswanath K. Health behavior and health education theory, research, and practice. 4th ed. San Francisco, CA: Jossey-Bass; 2008.

16- Milne S, Sheeran P, Orball SH. Prediction and intervention in health-related behavior: a meta-analytic review of protection motivation theory. J Appl Soc Psychol2000; 30(1): 106-43. 
17- Floyd DL, Prentic-Dunn S, Rogers RW. Ametaanalysis of research on protection motivationtheory. $J$ Appl Soc Psychol2000; 30(2): 407-29.

18- Beirens TMJ, Brug J, Van Beeck EF, Dekker R, Den Hertog P, Raat H. Assessing psychosocial correlates of parental safety behaviour using Protection Motivation Theory: Stair gate presence and use among parents of toddlers. Health Educ Res2008; 23(4): 723-31.

19- Beirens TMJ, Van Beeck EF, Brug J, Den Hertog P, Raat H. Why do parents with toddlers store poisonous products safely? Int J Pediatr2010; 2010.

20- Fathi-Shekhi M, Shamsi M, Khorsandi M, Heaidari M. Predictors accident structures in mothers with children under 5 years old in city of Khorramabad based on Health Belief Model. J Saf Promot Inj Prev2015; 3(3): 199-206. 21- Russell KM, Champion VL. Health beliefs and social influence in home safety practices of mothers with preschool children. J Nurs Scholarsh1996; 28(1): 59-64.

22-Hendrickson SG. Reaching an underserved population with a randomly assigned home safety intervention. Inj Prev2005; 11(5): 313-7.

23- Greening L, Stoppelbein L. Young drivers' health attitudes and intentions to drink and drive. $J$ Adolesc Health2000; 27(2): 94-101.

24- Smithson J, Garside R, Pearson M. Barriers to, and facilitators of, the prevention of unintentional injury in children in the home: A systematic review and synthesis of qualitative research. Inj Prev2011; 17(2): 119-26.

25- Morrongiello BA, Widdifield R, Munroe K, Zdzieborski D. Parents teaching young children home safety rules: implications for childhood injury risk. $J$ Appl Dev Psychol2014; 35(3): 254-61.

26- Morrongiello BA, McArthur BA, Bell M. Managing children's risk of injury in the home: does parental teaching about home safety reduce young children's hazard interactions? Accident. Anal Prev2014; 71: 194200.

27- Fathi-Shekhi M, Shamsi M, Khorsandi M, Ranjbaran M. The measurement of health belief model constructs in prevention of accident and injuries in children in Khorramabad, 2014. Arak Medical University Journal2015; 18(1): 69-77.

28- Laursen B, Nielsen JW. Influence of sociodemographic factors on the risk of unintentional childhood home injuries. Eur J Public Health2008; 18(4): 366-70.

29- Mulvaney C, Kendrick D. Engagement in safety practices to prevent home injuries in preschool children among white and non-white ethnic minority families. Inj Prev2004; 10(6): 375-8.

Copyright $\odot 2016$ ASP Ins. This open-access article is published under the terms of the Creative Commons Attribution-NonCommercial 4.0 International License which permits Share (copy and redistribute the material in any medium or format) and Adapt (remix, transform, and build upon the material) under the Attribution-NonCommercial terms. 